\title{
The Physical Activity Level, Body Composition and Diabetes Mellitus Influence the Association Between Depression and Hypertension in Community-Dwelling Elders
}

Carlos Geovane S. Araújo, ${ }^{\circledR}$ Ivna Vidal Freire, ${ }^{\circledR}$ Ícaro José Santos Ribeiro, ${ }^{\circledR}$ Yanne Franca Montino, ${ }^{\circledR}$ Cézar Augusto Casotti, ${ }^{\circledR}$ Rafael Pereira ${ }^{\circledR}$

Universidade Estadual do Sudoeste da Bahia (UESB), ${ }^{1}$ Jequie, BA - Brazil

\section{Abstract}

Background: Depression and hypertension are highly prevalent among elderly people. Although the relationship between these conditions is well recognized, however, the factors that may influence such association are not clearly understood.

Objective: To analyze the association between depression and hypertension in community-dwelling elders.

Methods: Two-hundred and thirty-one community-dwelling elders provided information regarding the following variables: sex, age, ethnicity, smoking habit, physical activity level (PA), body mass index (BMI) and diabetes mellitus (DM). These variables can potentially influence depression and hypertension, as well as its relationship. Screening for depression was made using the Geriatric Depression Scale (GDS). The presence of hypertension was defined based on self-reported data and/or the use of antihypertensive drugs. The logistic regression technique was applied, using hypertension as the dependent variable and depressive state as a predictive variable. Logistic regression was applied with and without adjustment for the potential intervening variables.

Results: The prevalence of depressive state and hypertension in the studied population was $14 \%$ and $59 \%$, respectively. The association between depression and hypertension without adjustments was not significant (odds ratio $[\mathrm{OR}]=2.28,95 \%$ confidence interval $[95 \% \mathrm{CI}]=0.98-5.32 ; \mathrm{p}=0.06$ ). However, after adjusting for $\mathrm{PA}$, $\mathrm{BMI}$ and DM, the strength of association between depression and hypertension significantly increased $(\mathrm{OR}=3.08$, $95 \% \mathrm{CI}=1.12-8.46 ; \mathrm{p}=0.03)$.

Conclusion: The association between depression and hypertension in the elderly is directly influenced by PA, BMI and DM. This finding may guide strategies to increase the adherence to a healthier lifestyle. (Int J Cardiovasc Sci. 2019;32(4):355-361)

Keywords: Aging, Mood Disorders; Hypertension; Diabetes Mellitus; Depression; Obesity, Sedentarism; Exercise; Independent Living; Lifestyle.

\section{Introduction}

Senescence is a natural life process associated with increased risk of non-communicable diseases, as hypertension. In fact, there is a growing prevalence of hypertension with increasing age. ${ }^{1}$ This is worrying, since it is expected that the world population over 60 years old will be approximately two billion in the next decades ${ }^{2}$ and the prevalence of hypertension could reach up to $80 \%$ among elders. ${ }^{3}$
Mailing Address: Rafael Pereira

Department of Biological Sciences, State University of Southwest of Bahia. Rua José Moreira Sobrinho, s/n. Postal Code: 45210-506, Jequiezinho Jequie, Bahia - Brazil.

E-mail: rafaelpereira@uesb.edu.br
Rafael Pereira, PhD

Head of the Integrative Physiology Research Center - Department of Biological Sciences Universidade Estadual do Sudoeste da Bahia (UESB)

rpfisiologia@gmail.com 
Hypertension is recognized as a multifactorial clinical condition, with lifestyle- related factors, such as smoking, high sodium intake, sedentary lifestyle, among others, widely associated with this condition. However, recent studies have pointed to a close relationship between hypertension and depression, ${ }^{4}$ which becomes even more worrying when considering the elderly people, due to the known association between depression and aging. ${ }^{5}$

Depressive disorder is common among the elderly; it is a multi-causal condition, whose etiology may vary from depressive disorders, observed in young adults, to those associated with chronic age-related processes (cardiovascular, inflammatory, endocrine, autoimmune processes), continuous use of some medications, psychological adversity, and cognitive deficits. ${ }^{6}$ Approximately $10 \%$ of individuals over 60 years old require therapeutic intervention for depressive disorder, and the prevalence of depression may be greater than $40 \%$ among elders living in geriatric institutions. ${ }^{7}$

Changes in autonomic nervous system control, characterized by worse vagal control and increased heart rate, are observed in depressive subjects and are pointed out as factors that may explain the predisposition to hypertension. ${ }^{8}$ In addition, it is known that, among elders, the association between depression and hypertension seems to be influenced by obesity. ${ }^{9}$

The study by Long et al., ${ }^{9}$ raises an important perspective in the understanding of the relationship between depression and hypertension among elders. In fact, Meng al., ${ }^{10}$ had already reported that variables such as gender, race, smoking, physical activity level, obesity / body mass index (BMI), DM and other psychological factors are potentially confounding variables in the relationship between depression and hypertension. In this context, the present study aimed to analyze the association between depression and hypertension in community-dwelling elders, as well as to analyze the influence of confounding variables that are potentially capable to influence this association.

\section{Material and methods}

\section{Sample}

All community-dwelling old adults ( $\geq 60$ years old) from Aiquara, Bahia, Brazil were invited to take part in this survey study. Two hundred eighty-nine subjects were screened, all of them answered an extensive health questionnaire, and were submitted to clinical and physical examinations. Bedridden individuals and / or those with severe cognitive impairment $(n=20)$ were excluded. Cognitive status was assessed using the translated and validated version of the Mini-Mental State Examination (MMSE). ${ }^{11}$ The cutoff points for cognitive impairment was set as: 13 points for no schooling, 18 points for schooling from 1 to 11 years, and 26 points for more than 11 years of schooling. ${ }^{11}$ Additionally, 38 elders had technical problems during data recording, which limited their inclusion in the analysis. Data were collected between January and July 2015.

\section{Ethical aspects}

The individuals included in this study were informed about all the procedures and provided written informed consent to participate. This study was approved by the ethics committee of the institution (CAAE: 10786212.3.0000.0055) and abides by the CONEP resolution 466/2012.

\section{Definition of hypertension and depression}

The stratification of hypertensive and normotensive elderly subjects was based on previous diagnosis reported by the elders, while the stratification of depressive and non-depressive elders was based on the Geriatric Depression Scale (GDS), which was validated to the Brazilian population. ${ }^{12}$ The cut-off score for depression was set as 6 positive items. ${ }^{13}$

The most commonly used psychotropic medications among depressive elders were tricyclic and selective serotonin-reuptake-inhibitors, benzodiazepines and muscle-relaxation drugs.

\section{Adjustment variables}

The dichotomous variables sex (male or female), race (white or non-white), smoking habit (yes or not), physical activity level (sufficiently active or insufficiently active), and self-reported diagnostic of DM (yes or no), and the continuous variables age and body mass index (BMI, $\mathrm{Kg} / \mathrm{m}^{2}$ ) was used as adjustment variables.

Physical activity level was obtained using the International Physical Activity Questionnaire (IPAQ) and the results were dichotomized according to the proposed cut-point of $\geq 150 \mathrm{~min} /$ week of moderate and vigorous activity (i.e., $\geq 150 \mathrm{~min} / \mathrm{wk}$, sufficiently active; $<150$ $\mathrm{min}$ / week, insufficiently active). ${ }^{14}$ 


\section{Statistical analysis}

The chi-square test was used to identify differences in proportions between hypertensive and normotensive groups, and between depressive and non-depressive groups. Distribution of dichotomous variables (sex, race, smoking habit, physical activity level, and previous DM) was tested; for continuous variables, normality of distribution was tested with KolmogorovSmirnov test. As the assumption of normality was rejected, the Mann-Whitney test was used for comparisons of age and BMI between hypertensive and normotensive groups, and between depressive and non-depressive groups.

Descriptive analyses were made using absolute and relative frequencies (dichotomous variables), and median and interquartile interval (continuous variables). The association between hypertension and depression was tested by a logistic regression method. Additionally, the variables that achieved a significance level of $\mathrm{p}<0.1$ in the chi-square test (categorical variables) or in the Mann-Whitney test (continuous variables) were included as adjustment variable in the logistic regression, as proposed by Conover. ${ }^{15}$ Then, logistic regressions were conducted with and without adjustment for each eligible variable, and with adjustment including all eligible variables together. A significance level of $p<0.05$ was used for analyses using the chi-square test, the MannWhitney test and logistic regressions, and all procedures were performed using tge IBM SPSS V.21.0 (SPSS, IBM Corporation, Armonk, New York, USA).

\section{Results}

In the study population, the prevalence of depressive state was $14 \%$ and of hypertension was $59 \%$. Hypertensive elderly subjects had significantly higher BMI compared with normotensive subjects $\left(27.20 \pm 5.75 \mathrm{~kg} / \mathrm{m}^{2}\right.$ vs, $23.80 \pm 7.13 \mathrm{~kg} / \mathrm{m}^{2}, \mathrm{p}<0.05$. Age was not different between hypertensive and normotensive elders $(72.00 \pm 11.00$ years old vs. 71.00 \pm 13.00 years old, respectively, $p>0.05$ ). Hypertension was significantly associated with DM $(\mathrm{p}<0.05)$, while the variables sex, race, smoking habits, and physical activity level were not significantly associated ( $p>$ 0.05). Table 1 shows the association of categorical variables (sex, race, smoking habits, DM and physical activity level) with hypertension.

Depressive elders were significantly older than nondepressive elders $(76.00 \pm 11.50$ vs. $71.00 \pm 11.00$ years old, $\mathrm{p}<0.05)$. Regarding BMI, there was no significant difference between depressive and non-depressive elders $\left(25.20 \pm 6.95 \mathrm{~kg} / \mathrm{m}^{2}\right.$ vs. $25.60 \pm 7.33 \mathrm{~kg} / \mathrm{m}^{2}$, respectively, $\mathrm{p}>0.05)$. Depression was significantly associated with physical activity level ( $p<0.05)$, but not with the variables sex, race, smoking habit, and diabetes mellitus were not significantly associated $(p>0.05)$. Table 1 shows the association of categorical

Table 1 - Absolute and relative frequency of sex, race, diabetes mellitus, smoking habits and physical activity level of elderly individuals ( $\mathrm{n}=94)$ according to blood pressure status (hypertension vs normotensive), Aiquara, Bahia, Brazil (2015)

\begin{tabular}{|c|c|c|c|c|}
\hline & & Normotensive & Hypertensive & p value \\
\hline \multirow{3}{*}{ Sex } & Women & $52(55.3 \%)$ & $86(62.3 \%)$ & \multirow{3}{*}{0.256} \\
\hline & & & & \\
\hline & Men & $42(44.7 \%)$ & $51(37.2 \%)$ & \\
\hline \multirow{3}{*}{ Race } & White & $15(16.3 \%)$ & $17(13.2 \%)$ & \multirow{3}{*}{0.515} \\
\hline & & & & \\
\hline & Others (pardo and black) & $77(83.7 \%)$ & $112(86.8 \%)$ & \\
\hline \multirow[b]{2}{*}{ Smoker } & No & $79(87.8 \%)$ & $114(91.2 \%)$ & \multirow[b]{2}{*}{0.414} \\
\hline & Yes & $11(12.2 \%)$ & $11(8.8 \%)$ & \\
\hline \multirow[b]{2}{*}{ Diabetes mellitus } & No & $84(89.4 \%)$ & $99(72.3 \%)$ & \multirow[b]{2}{*}{$0.002^{*}$} \\
\hline & Yes & $10(10.6 \%)$ & $38(27.7 \%)$ & \\
\hline \multirow{2}{*}{ Physical activity level } & Sufficiently active ( $\geq 150 \mathrm{~min} /$ week) & $48(53.9 \%)$ & $53(57.5 \%)$ & \multirow{2}{*}{0.605} \\
\hline & Insufficiently active (< $150 \mathrm{~min} /$ week) & $41(46.1 \%)$ & $54(52.5 \%)$ & \\
\hline
\end{tabular}


Table 2 - Absolute and relative frequency of sex, race, diabetes mellitus, smoking habit and physical activity level of elderly individuals $(n=197)$ according to depressive status (non-depressive vs depressive), Aiquara, Bahia, Brazil (2015)

\begin{tabular}{|c|c|c|c|c|}
\hline & & Non-depressive & Depressive & p value \\
\hline \multirow{2}{*}{ Sex } & Women & $117(59.4 \%)$ & $19(59.4 \%)$ & \multirow{2}{*}{0.999} \\
\hline & Men & $80(40.6 \%)$ & $13(40.6 \%)$ & \\
\hline \multirow{2}{*}{ Race } & White & $30(15.8 \%)$ & $2(6.7 \%)$ & \multirow{2}{*}{0.188} \\
\hline & Others (pardo and black) & $160(84.2 \%)$ & $28(93.3 \%)$ & \\
\hline \multirow[b]{2}{*}{ Smoker } & No & $166(90.2 \%)$ & $26(86.7 \%)$ & \multirow[b]{2}{*}{0.553} \\
\hline & Yes & $18(9.8 \%)$ & $4(13.3 \%)$ & \\
\hline \multirow{2}{*}{ Diabetes mellitus } & No & $160(81.2 \%)$ & $22(68.8 \%)$ & \multirow[b]{2}{*}{0.105} \\
\hline & Yes & $37(18.8 \%)$ & $10(31.3 \%)$ & \\
\hline \multirow{2}{*}{ Physical activity level } & Sufficiently active ( $\geq 150 \mathrm{~min} /$ week) & $109(58.9 \%)$ & $11(36.7 \%)$ & \multirow{2}{*}{$0.023^{*}$} \\
\hline & Insufficiently active ( $<150 \mathrm{~min} /$ week) & $76(41.1 \%)$ & $19(63.3 \%)$ & \\
\hline
\end{tabular}

variables (sex, race, smoking habits, diabetes mellitus and physical activity) with hypertension.

Since the variables DM, BMI, and physical activity level were associated with hypertension and depression, logistic regression analysis was performed, with and without adjustments for the cited variables. Table 3 shows the regression coefficient, and the odds ratio (OR) and its $95 \%$ confidence interval of the variables included in the adjusted and unadjusted logistic regression analysis. It is possible that the association between hypertension and depression was directly influenced by BMI, and physical activity level, while the analysis adjusted for all the variables (DM, BMI and physical activity level) together also confirmed the significant influence of these variables on the relationship between depression and hypertension in community-dwelling elders.

\section{Discussion}

The present study aimed to analyze the association between depression and hypertension in communitydwelling elders, and to analyze the influence of potential confounding variables. Our results showed that the association between depression and hypertension was significantly influenced by BMI, physical activity level and DM.

In fact, no significant association was found between depression and hypertension $(\mathrm{OR}[95 \% \mathrm{CI}]=2.28[0.98$
- 5.32]; $\mathrm{p}=0.06)$ when analyzed without adjustment variables. However, after adjustment for the variables BMI (OR [CI95\%] = 2.66 [1.04 - 6.79], p = 0.04) and physical activity level (OR [CI95\%] = 3.41 [1.31 - 8.85], $\mathrm{p}=0.01)$ a significant association was found between depression and hypertension in the study population. The analysis adjusted for BMI, physical activity level and DM together also influenced significantly the association between depression and hypertension $(\mathrm{OR}[95 \% \mathrm{CI}]=3.08$ [1.12 - 8.46]; $\mathrm{p}=0.03)$.

In our study, DM was significantly associated with hypertension, but not with depression, which may explain the lack of influence of the adjustment for DM on the association between hypertension and depression. Previous studies have shown that DM is common among depressed people, ${ }^{16,17}$ in fact, in our study, $31.3 \%$ of depressed elderly people were diabetic, whereas this prevalence was only $18.8 \%$ among non-depressed elderly people. However, no significant difference was achieved. Despite this, the considerably higher prevalence of diabetic elderly among depressive and (statistically significant) hypertensive elders justifies the maintenance of this intervening variable (i.e., DM) in the regression model adjusted for DM, BMI and level of physical activity.

The close association of obesity with depression ${ }^{18,19}$ and hypertension ${ }^{20,21}$ explains the strong influence of this variable on the relationship between depression 
Table 3 - Regression coefficient, odds ratio (OR) and its $95 \%$ confidence interval of the variables included in the adjusted and unadjusted logistic regression analysis

\begin{tabular}{|c|c|c|c|c|c|}
\hline Variable & $\begin{array}{c}\text { Regression } \\
\text { coefficient (RC) }\end{array}$ & Standard error & Odds ratio (OR) & $95 \%$ CI & p value \\
\hline \multicolumn{6}{|l|}{ Unadjusted } \\
\hline Depression & 0.823 & 0.433 & 2.28 & $0.98-5.32$ & 0.06 \\
\hline Constant & 0.276 & - & - & - & - \\
\hline \multicolumn{6}{|c|}{ Adjusted for diabetes mellitus } \\
\hline Depression & 0.731 & 0.441 & 2.08 & $0.86-4.93$ & 0.09 \\
\hline Constant & 0.093 & - & - & - & - \\
\hline \multicolumn{6}{|c|}{ Adjusted for body mass index } \\
\hline Depression & 0.977 & 0.479 & 2.66 & $1.04-6.79$ & $0.04^{*}$ \\
\hline Constant & -3.00 & - & - & - & - \\
\hline \multicolumn{6}{|c|}{ Adjusted for physical activity level } \\
\hline Depression & 1.23 & 0.486 & 3.41 & $1.31-8.85$ & $0.01^{*}$ \\
\hline Constant & 0.348 & - & - & - & - \\
\hline \multicolumn{6}{|c|}{ Adjusted for diabetes mellitus, BMI and physical activity level } \\
\hline Depression & 1.124 & 0.516 & 3.08 & $1.12-8.46$ & $0.03^{*}$ \\
\hline Constant & -2.515 & - & - & - & - \\
\hline
\end{tabular}

and hypertension. Follow-up studies have corroborated such relationship, since the presence of obesity increases by 1.55 times the odds to develop depression, just as depression increases 1.58 times the odds to develop obesity. ${ }^{19-22}$ Therefore, a higher cardiovascular risk comes from the association of these conditions, i.e., obesity and depression. ${ }^{18,23}$

The adoption of a physically active lifestyle has been pointed out as an effective behavioral intervention to treat depression symptoms. ${ }^{24,25}$ Josefsson et al., ${ }^{26}$ in a systematic review with meta-analysis on this issue, concluded that the use of exercise as an intervention generates positive results in mild-to-moderate depression. Blake et al. ${ }^{27}$ stated that physical activity programs can achieve positive results in the treatment of depressive symptoms in the elderly.

The recent study of Holmquist et al. ${ }^{28}$ broadens the basis of these findings. In the cited study, the authors evaluated the association of depression with several lifestyle-related variables, previous illnesses and physical performance in the elderly. It was observed that depressed elders (GDS $\geq 5$ points) were predominantly obese, diabetic, and physically less active (or had worse physical performance). In fact, these same variables may be associated with hypertension, and thus can influence the association between hypertension and depression. In this sense, two aspects are relevant: 1) the identification of depressive, obese, diabetic and insufficiently active elderly subjects can guide the screening of those prone to hypertension, since this set of factors among elders increases in 3.08 (1.12 - 8.46) times the odds of being hypertensive; 2 ) all the studied factors associated with hypertension and depression here are amenable to intervention; thus, as proposed by Blake et al., ${ }^{27}$ preventive strategies focused on physical activity could represent an excellent strategy from the point of view of cost-effectiveness to prevent hypertension in depressed elderly people, since the level of physical activity increases $3.41(1.31$ - 8.85) times the odds of a depressed elderly subject being hypertensive. 


\section{Conclusion}

Our results showed that BMI, DM and physical activity level influence the association between hypertension and depression in community-dwelling elders. DM affects the association between depression and hypertension when combined to physical activity and BMI. In addition, the level of physical activity seems to be the main influencing factor of this relationship. This promotes positive perspectives regarding therapeutic interventions, since, unlike drug interventions, the adoption of a physically active lifestyle is an excellent, cost-effective intervention for both hypertension and depression.

\section{Author contributions}

Conception and design of the research: Cassoti CA, Ribeiro IJS and Pereira R. Acquisition of data: Araújo CGS, Freire IV and Ribeiro IJS. Analysis and interpretation of the data: Pereira R, Casotti CA, Montino YF. Statistical analysis: Pereira R, Ribeiro IJS. Obtaining financing: Casotti CA and Pereira R. Writing of the manuscript: Araújo CGC, Freire IV, Montino YF. Critical

\section{References}

1. Lionakis N, Mendrinos D, Sanidas E, Favatas G, Georgopoulou M. Hypertension in the elderly. World J Cardiol. 2012;4(5):135-47.

2. World Health Organization.(WHO) "Ageing well" must be a global priority [Internet]. Geneva;2014. [acesso em 30 abr 2019]. Disponível em: https: / / www.who.int/mediacentre/news/ releases/2014/lancetageing-series/en/

3. Patel A, Stewart BF. On hypertension in the elderly: an epidemiologic shift [Internet]. Washington DC: American College of Cardiology; 2015. [acesso em 30 abr 2019]. Disponível em: https: / / www.acc.org/ latest-incardiology / articles / 2015/02/19/14/55/on-hypertension-in-the-elderly

4. Rubio-Guerra AF, Rodriguez-Lopez L, Vargas-Ayala G, HuertaRamirez S, Serna DC, Lozano-Nuevo JJ. Depression increases the risk for uncontrolled hypertension. Exp Clin Cardiol. 2013;18(1):10-2.

5. Djernes JK. Prevalence and predictors of depression in populations of elderly: a review. Acta Psychiatr Scand. 2006;113(5):372-87.

6. Alexopoulos GS. Depression in the elderly. Lancet. 2005;365(9475):196170 .

7. Cipriani A, Barbui C, Butler R, Hatcher S, Geddes J. Depression in adults: drug and physical treatments. BMJ Clin Evid. 2011 May 25;2011:pii:1003.

8. Scalco AZ, Scalco MZ, Azul JB, Lotufo Neto F. Hypertension and depression. Clinics. 2005;60(3):241-50.

9. Long J, Duan G, Tian W, Wang L, Su P, Zhang W, et al. Hypertension and risk of depression in the elderly: a meta-analysis of prospective cohort studies. J Hum Hypertens. 2015;29(8):478-82. revision of the manuscript for intellectual content: Casotti CA, Pereira R and Ribeiro IJS.

\section{Potential Conflict of Interest}

No potential conflict of interest relevant to this article was reported.

\section{Sources of Funding}

There were no external funding sources for this study.

\section{Study Association}

This study is not associated with any thesis or dissertation work.

\section{Ethics approval and consent to participate}

This study was approved by the Ethics Committee of the Universidade Estadual do Sudoeste da Bahia (UESB) under the protocol number 171464. All the procedures in this study were in accordance with the 1975 Helsinki Declaration, updated in 2013. Informed consent was obtained from all participants included in the study.
10. Meng L, Chen D, Yang Y, Zheng Y, Hui R. Depression increases the risk of hypertension incidence. J Hypertens. 2012;30(5):842-51.

11. Bertolucci PHF, Brucki SMD, Campacci SR, Juliano Y. The mini-mental state examination in an outpatient population: influence of literacy. Arq Neuro-Psiquiatr. 1994;52(1):01-7.

12. Almeida OP, Almeida SA. Reliability of the Brazilian version of the Geriatric Depression Scale (GDS) short form. Arq Neuro-Psiquiatr. 1999;57(2B):421-6.

13. Burke WJ, Roccaforte WH, Wengel SP. The short form of the geriatric depression scale: a comparison with the 30 -item form. J Geriatr Psychiatry Neurol. 1991;4(3):173-8.

14. World Health Organization [internet]. Global recommendations on physical activity for health. Geneva: WHO; 2010 [acesso em $30 \mathrm{abr}$ 2019]. Disponível em: https://www.who.int/dietphysicalactivity/ factsheet_recommendations/en/

15. Conover WJ. Practical nonparametric statistics. 3rd ed. New York: John Wiley \& Sons; 1999.

16. Katon WJ. The comorbidity of diabetes mellitus and depression. Am J Med. 2008;121(11 Suppl 2):S8-15.

17. Sweileh WM, Abu-Hadeed HM, Al-Jabi SW, Zyoud SH. Prevalence of depression among people with type 2 diabetes mellitus: a cross sectional study in Palestine. BMC Public Health. 2014 Feb 13;14:163.

18. Pratt LA, Brody DJ. Depression and obesity in the U.S. adult household population, 2005-2010. NCHS Data Brief. 2014 Oct;(167):1-8. 
19. Carey M, Small H, Yoong SL, Boyes A, Bisquera A, Sanson-Fisher R. Prevalence of comorbid depression and obesity in general practice: a cross-sectional survey. Br J Gen Pract. 2014;64(620):e122-7.

20. Davy KP, Hall JE. Obesity and hypertension: two epidemics or one? Am J Physiol Integr Comp Physiol [Internet]. 2004 May [cited 2018 Dec 11];286(5):R803-13. Available from: http:/ / www.ncbi.nlm.nih.gov/ pubmed/ 15068965

21. do Carmo JM, da Silva AA, Wang Z, Fang T, Aberdein N, de Lara Rodriguez CEP, et al. Obesity-induced hypertension: brain signaling pathways. Curr Hypertens Rep. 2016;18(7):58.

22. Luppino FS, de Wit LM, Bouvy PF, Stijnen T, Cuijpers P, Penninx BW, et al. Overweight, obesity, and depression: a systematic review and metaanalysis of longitudinal studies. Arch Gen Psychiatry. 2010;67(3):220-9.

23. Katon $\mathrm{W}$, Ciechanowski P. Impact of major depression on chronic medical illness. J Psychosom Res. 2002;53(4):859-63.
24. Craft LL, Perna FM. The benefits of exercise for the clinically depressed. Prim Care Companion J Clin Psychiatry. 2004;6(3):104-11.

25. Kvam S, Kleppe CL, Nordhus IH, Hovland A. Exercise as a treatment for depression: a meta-analysis. J Affect Disord. 2016 Sep 15;202:67-86.

26. Josefsson T, Lindwall M, Archer T. Physical exercise intervention in depressive disorders: meta-analysis and systematic review. Scand J Med Sci Sports. 2014;24(2):259-72.

27. Blake H, Mo P, Malik S, Thomas S. How effective are physical activity interventions for alleviating depressive symptoms in older people? a systematic review. Clin Rehabil. 2009;23(10):873-87.

28. Holmquist S, Mattsson S, Schele I, Nordström P, Nordström A. Low physical activity as a key differentiating factor in the potential highrisk profile for depressive symptoms in older adults. Depress Anxiety. 2017;34(9):817-25. 